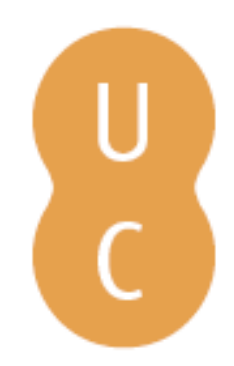

\title{
pompalina
}

\section{A Faculdade de Matemática e os estudos matemáticos na reforma pombalina}

Autor(es): Bebiano, Natália

Publicado por: Imprensa da Universidade de Coimbra

URL

persistente: URI:http://hdl.handle.net/10316.2/32272

DOI: $\quad$ DOI:http://dx.doi.org/10.14195/978-989-26-0413-8_5

Accessed : $\quad$ 26-Apr-2023 16:15:07

A navegação consulta e descarregamento dos títulos inseridos nas Bibliotecas Digitais UC Digitalis, UC Pombalina e UC Impactum, pressupõem a aceitação plena e sem reservas dos Termos e Condições de Uso destas Bibliotecas Digitais, disponíveis em https://digitalis.uc.pt/pt-pt/termos.

Conforme exposto nos referidos Termos e Condições de Uso, o descarregamento de títulos de acesso restrito requer uma licença válida de autorização devendo o utilizador aceder ao(s) documento(s) a partir de um endereço de IP da instituição detentora da supramencionada licença.

Ao utilizador é apenas permitido o descarregamento para uso pessoal, pelo que o emprego do(s) título(s) descarregado(s) para outro fim, designadamente comercial, carece de autorização do respetivo autor ou editor da obra.

Na medida em que todas as obras da UC Digitalis se encontram protegidas pelo Código do Direito de Autor e Direitos Conexos e demais legislação aplicável, toda a cópia, parcial ou total, deste documento, nos casos em que é legalmente admitida, deverá conter ou fazer-se acompanhar por este aviso. 
João Rui Pita

Coordenaçáo

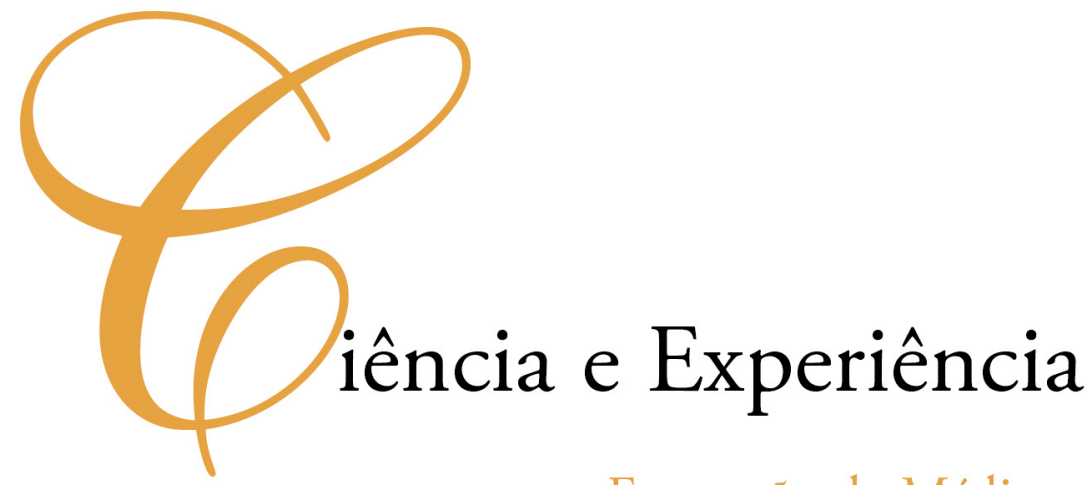

Formação de Médicos, Boticários, Naturalistas e Matemáticos

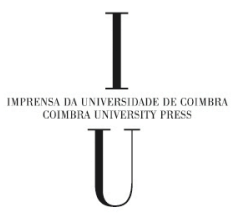

- COIMBRA 2006 
Natália Bebiano

Departamento de Matemática

Faculdade de Ciências e Tecnologia da Universidade de Coimbra

A FACUldade de matemática e os

ESTUdOS MATEMÁTICOS NA REFORMA POMBALINA

... Ob feliz de quem entende

de quem busca e surpreende

os pontos, a recta e o plano!...

António Gedeão, in «Sou assim»

Os Estudos Matemáticos desde a Fundação da Universidade a Pedro Nunes

Existe em Portugal uma escassa tradição de cultivo das Ciências Exactas. Um bosquejo pela História do nosso Ensino é revelador de um quadro, em que estes estudos estão ausentes ou são desenvolvidos com fraco zelo. Aquando da fundação da Universidade em 1290, foram criadas as Faculdades de Artes, Leis, Cânones, Medicina e, cerca de 1380, a de Teologia. Na estrutura curricular da Universidade não há menção a estudos matemáticos. Os corpos de saber privilegiados são Direito Canónico, Direito Civil e Teologia.

Em 1431, o Infante D. Henrique, primeiro protector da Universidade, motivado pelas necessidades práticas da navegação, doou casas às Escolas Gerais em Lisboa, a fim de nelas serem estudadas as Artes do Quadrivium, que incluíam Astronomia, Música, Aritmética e Geometria. Foi, então, criada a Aula da Sphera. 
Se o estudo das Ciências Matemáticas no Reino se iniciou nessa ocasião, ou se já existia ainda que não institucionalizado, é incerto.

A nível elementar, o ensino destas ciências é igualmente incipiente, surgindo ligado às artes médicas, astrologia, magia e curandeirismo. Nas escolas religiosas, como a de Santa Cruz de Coimbra, a de Alcobaça, a de Braga ou a da Colegiada de Santa Maria da Oliveira de Guimarães, os curricula eram essencialmente voltados para o ensino da Gramática (Latim), da Dialéctica (Lógica), além da Teologia e da Música para futuros clérigos.

A promoção dos estudos matemáticos pelo Infante D. Henrique não teve frutos imediatos. Os cosmógrafos continuaram a ser recrutados no estrangeiro, caso de Jácome de Maiorca, só mais tarde surgindo os contributos portugueses à Astronomia e à Cartografia.

O primeiro livro impresso ligado à Matemática e à Astronomia foi o $\mathrm{Al}$ manach Perpetuum de Abraão Zacuto, publicado em Lisboa em 1496, cerca de uma década volvida sobre a impressão da primeira obra em Portugal (1485). Em 1519, Gaspar Nicolas publicou o Tratado da pratica Darismetyca, tratado de aritmética comercial para apoio ao comércio e navegação, sem grande originalidade e influenciado pela obra de Frei Lucas de Burgo. Além destas, outras obras de análoga índole vieram à luz, mas sem contributos inovadores assinaláveis.

Em 1537, a Universidade, que desde 1290 funcionara alternadamente em Lisboa e Coimbra, foi transferida definitivamente para Coimbra, mudança esta acompanhada da reforma dos estudos e do recrutamento de novos docentes, entre eles alguns estrangeiros. A brisa de um Humanismo sábio soprou a Instituição, que atravessou um período de relativo brilho, salientando-se, entre os seus mais ilustres mestres, Pedro Nunes.

Pedro Nunes é o mais notável matemático português de sempre. Estudou Medicina em Lisboa e Salamanca, foi nomeado professor de Matemática e Astronomia da Universidade e, em 1547, cosmógrafo-mor do Reino. Na área das ciências exactas, o seu Libro de Algebra en Arithmetica y Geometria publicado em 1567 - em espanhol, em guisa de maior divulgação, e escrito em português vinte anos antes - é um dos mais famosos tratados 
no período compreendido entre a Ars Magna de Cardano (1545) e a Artem Analyticam Isagoge (1591) de Vieta.

Relativamente ao treino dos navegadores portugueses, escreve Pedro Nunes, que os nossos navegantes se não aventuraram ao acaso, mas na posse de um saber instrumental fundado na descoberta das leis da Natureza, partindo ... muito ensinados e providos de instrumentos e regras de astrologia e geometria. (Pedro Nunes, Tratado Em Defensam da Carta de Marear).

Durante o século XVI, a atmosfera do Humanismo repercutiu-se no Reino abrindo perspectivas inovadoras ao pensamento e estimulando a criatividade. Os nossos cientistas náuticos, pilotos, navegadores, geógrafos, cartógrafos dão ao mundo novos saberes, de Botânica, Geografia, Astronomia, Náutica, Cartografia.

\section{A Universidade em finais do século XVI}

Depois de Alcácer-Quibir, sob a regência de D. Catarina ou do Cardeal D. Henrique, o Reino já não é o Portugal de Quinhentos. Desenvolve-se uma atitude mental sem grandes ânsias científicas, alguns não entendem mesmo o cultivo de actividades sem utilidade imediata, pelo que, nas Cortes de 1562 , se foi ao ponto de pedir que:

... os estudos de Coimbra se desfaçam por serem prejudiciais ao reino, e a renda se aplique para a guerra, e quem quiser aprender vá a Salamanca ou Paris, e não haverá tanto letrado sobejo nem tantas demandas.

Em 1580, o Reino perde a independência; Pedro Nunes morre em 1578 sem deixar discípulos. Sucede-lhe André de Avelar, que é afastado e perseguido pela Inquisição, ficando vaga a cadeira de Matemática em 1620. A cadeira de Matemática passou então a ser intermitentemente provida e, em 1681, o jesuíta suíço João dos Reis (König) veio de Friburgo para se encarregar da sua regência entre 1682 e 1685. 
Durante os 60 anos de domínio filipino, alguns mestres espanhóis famosos ensinaram em Coimbra, entre todos avultando Francisco Suarez, mas o sentido renovador alcançado na Universidade foi-se esvaindo, prevalecendo o espírito da Contra-Reforma e a defesa dos valores ortodoxos, em desfavor da renovação. A Universidade fecha-se nos seus dogmas sem participar no progresso científico que desponta na Europa. Os métodos de ensino e a organização universitária propiciam a estagnação e, como Joaquim de Carvalho aponta, ... a obrigatoriedade de (seguir) textos e daí a escravidão do mestre ao já sabido; [...]; a ausência de ensino prático; [...]; o gosto e cultivo das disputas ... trouxe consigo a esterilidade do ensino e o seu isolamento da cultura contemporânea; [...]

\section{A Companhia de Jesus e o monopólio do ensino}

A Companhia de Jesus, introduzida em Portugal no século XVI, alcançou domínio completo na educação do Reino, orientando com exclusividade o nosso ensino. Criara escolas em todo o Reino, três das quais de grande projecção: o Colégio das Artes, em Coimbra, a Universidade de Évora, o Colégio de Santo Antão, em Lisboa, onde funcionou a Aula da Esfera, desde finais do século XVI até ao século XVIII, de nível elementar e sobretudo com objectivos de aplicações à Náutica.

Os mestres de Filosofia do Colégio das Artes, mestres conimbricenses, redigiram em latim o chamado "Curso Conimbricense», publicado entre os últimos anos do século XVI e a primeira década do século XVII, curso que era seguido nas suas escolas no Reino. Como diz Gomes Teixeira, ... a Ordem subiu em influência até conquistar o domínio completo da instrução universitária e depois o de toda a instrução nacional. ... Decaíram todos os ensinos, excepto o da Filosofia e o da Teologia, únicas ciências que mereceram a atenção dos invasores do ensino português.

O Reino sofria as consequências nefastas da expulsão dos judeus e vivia sob o jugo do Santo Tribunal. As Ciências das Quimeras prevaleciam sobre as 
Ciências da Razão, a Matemática, a Física, ou a Filosofia Natural. A doutrina aristotélico-tomista, síntese do saber de Aristóteles e de S. Tomás de Aquino, sancionada pela Igreja Católica Romana, encontrava-se profundamente arreigada na corrente dominante, asfixiando as vozes dissonantes. Desafiar o seu modelo dogmático, monolítico, de entender a realidade era uma atitude apodada de herética, mal tolerada pelas autoridades políticas e religiosas.

A despeito das reformas que desde o século XVI ocorreram na Universidade de Coimbra, a Instituição permaneceu fechada à renovação filosófica do cartesianismo e aos progressos científicos das Academias que floresciam nos países cultos. Os jesuítas foram, por alguns, considerados os viciadores conscientes dessas reformas e a visão anti-jesuítica vingou na historiografia portuguesa. A Universidade era uma espécie de corporação teocrática, onde a Escolástica imperava, alheia às profundas transformações científicas em curso.

As insuficiências da doutrina escolástica face ao impulso da investigação experimental e a imutabilidade do dogmatismo docente tornaram-se insustentáveis. A reinterpretação de Aristóteles revelou-se imprescindível. Porém, tal reinterpretação revelar-se-ia insuficiente e impossível de compatibilizar com o quadro newtoniano moderno. O saber rigoroso, matematizado, alicerçado na experiência, substituíra o saber prolixo, verbalista, dogmático e monolítico dos peripatéticos. E não havia obstinação ideológica ou religiosa capaz de vencer os factos.

\section{Portugal e a Revolução Científica}

Sendo certo que os Descobrimentos Portugueses contribuíram para o processo que conduziu à "Revolução Científica» dos séculos XVI e XVII, um olhar sobre o Portugal de Seiscentos revela que o Reino ocupou uma posição perfeitamente periférica nessa «revolução» de que a Europa era palco. Essa periferalidade tanto era a nível de criação de saber como da difusão das novas ideias. Nesse longo lapso de tempo, as Universidades de 
Coimbra e Évora, orientadas pelos jesuítas, procuraram adaptar-se às novas premissas intelectuais reformulando a Escolástica. Porém, o novo quadro epistemológico da Ciência exigia uma mudança radical.

As obras dos grandes Filósofos de Seiscentos, Galileu, Leibnitz, Newton, Descartes, conheceram dificuldades de penetração em Portugal, subjugadas pelas doutrinas tradicionais da Escolástica. Segundo Luís de Albuquerque, os contributos de Copérnico e Galileu nos textos portugueses do século XVII são considerados ou perfeitamente dispensáveis, ou redondamente falsos, ou aceites numa atitude meramente interpretativa, mas não explicativa da essência do Universo.

Garção Stockler observa que os nossos lentes, mesmo os mais insignes (como André de Avelar ou Frei Nicolau Coelho), ainda se encontravam voltados para a leitura de Alfargano, Albategenio e outros autores árabes, em lugar de estudarem as obras de Galileu, Kepler e Copérnico. Assim se dava voga a uma ciência do rigor sem rigor, a uma Física e a uma Matemática forjadas na imaginação e nos delírios da astrologia.

Também as ideias de Newton demoraram a ser aceites em Portugal. D'Alembert não escondeu a sua surpresa por, em 1750, ainda se mandar imprimir numa capital europeia - Lisboa - um trabalho intitulado: Systema aristotelicum de formis substancialibus et accidentibus absolutis.

Jacob de Castro Sarmento foi quem introduziu no Reino as teorias físicas de Newton, as quais tem entrado por toda a Europa, menos Portugal, e Espanha, sem encontrar a menor resistência. Em 1737, traduziu deste autor a Teórica Verdadeira das Marés, escrevendo na dedicatória ao conde de Monsanto que era seu objectivo ... a introducçam da verdadeira Philosophia Natural, ou Newtoniana nesse Reyno. [...] Pois he caso lastimoso [...] que quando em todas as Nações da Europa se estam aproveitando do (seu) benefício [...] estejam os nossos Portuguezes [...] perdendo o seu tempo [...] com huma Philosophia falsa, inútil e contenciosa.

Deveras, ao contrário do afirmado por Jacob de Castro Sarmento, as concepções de Newton, em particular, a teoria da gravitação, não tiveram 
acolhimento imediato na Europa. Leibnitz rejeitara-as, insurgindo-se contra a ressurreição das qualidades escolásticas e das potências quiméricas. Maupertius, a propósito da introdução destas doutrinas em França, afirma:

Foi necessário mais de meio século para familiarizar as Academias do continente com a atracção. Ela permanecia encerrada na sua ilha; ou, se atravessava o mar, não parecia senão a reprodução de um monstro que acabava de ser proscrito.

\section{Os estudos matemáticos em Portugal no primeiro meio século setecentista}

Os novos e notáveis avanços da Cultura e da Ciência repercutiram-se em Portugal durante o reinado de D. João V. Alguns estudiosos rumaram daqui para o estrangeiro e alcançaram notoriedade. Por exemplo, Barros e Vasconcelos distinguiu-se na Astronomia, publicando uma memória (1753) na Academia Real das Ciências de Paris que lhe deu ingresso na Academia das Ciências e Belas Letras de Berlim.

O estabelecimento por D. João V da Casa de Nossa Senhora das Necessidades da Congregação do Oratório, com uma excelente biblioteca, um gabinete de Ciências Naturais devidamente apetrechado e uma tipografia, representa o fim do monopólio de ensino pelos jesuítas. Os oratorianos são os primeiros a criticar publicamente os seus métodos pedagógicos, introduzindo inovações. O confronto entre jesuítas e oratorianos pela hegemonia do ensino é, desde logo, um reflexo visível da afirmação das novas ideias no Reino.

O Rei assiste às mostras de Física do Padre de Teodoro de Almeida na Congregação do Oratório de Lisboa, onde funciona em 1750 uma aula de Física Experimental que, pela defesa que faz do método experimental, será objecto de viva polémica. D. João V funda a importante Biblioteca da Universidade de Coimbra, cria a Academia Real de História Portuguesa (1720) 
e procede-se à reestruturação do Arquivo Nacional da Torre do Tombo (1721). Também os estudos militares foram promovidos, com a fundação da Academia Militar da Corte (1732) e das Praças de Valença do Minho, Praça de Elvas e Praça de Almeida.

No que concerne à Matemática na Universidade de Coimbra, era ministrada numa cadeira na Faculdade de Medicina de funcionamento intermitente. Os jesuítas, reconhecendo a necessidade de desenvolver o seu estudo como condição de entendimento das doutrinas filosóficas do sistema moderno, fazem com que D. João V mande vir de Itália os jesuítas Cappace e Carbone. Visavam fomentar o desenvolvimento das Ciências Matemáticas que lhes permitisse ir ao encontro das novas correntes. Porém, o intento será gorado e a missão científica destes padres italianos não deixará marcas apreciáveis.

O último lente a ocupar a cadeira de Matemática em Coimbra foi o beneditino Inácio de Ataíde, que sucedera ao jesuíta João Reis (König) 1682-1685. Referindo-se à longa vagatura da cadeira, D. Francisco de Lemos escreve em 1772, que a última (vagatura) foi de mais de sessenta anos. Mais afirma que ... o estudo desta ciência se achava inteiramente abandonado na Universidade (vide Relação Geral do Estado da Universidade, p. 45).

Fora da Universidade, a Matemática era estudada consoante motivações práticas, aplicações às actividades militares, levantamentos de cartas geográficas e topográficas e outros trabalhos de engenharia. Neste campo, distinguiu-se Manuel de Azevedo Fortes que estudou em Inglaterra e França, ensinou na Universidade de Sena e, de regresso a Portugal, publicou Engenheiro Portuguez (1728 e 1729), livro que contém um tratado de geometria prática e trigonometria plana. Em 1744, Fortes publicou a Logica racional, geometria e analytica introduzindo no Reino de forma sistematizada as ideias de Descartes. Depois da sua morte em 1749, o ensino da engenharia foi em contínua decadência (Stockler, Ensaio Histórico, p. 58).

Nos seus colégios, os jesuítas cultivavam a Matemática, mas não indo significativamente além das matérias elementares. O padre Inácio Monteiro, 
espírito esclarecido e culto, escreveu Elementos de Matemática e Manuel de Campos, em 1735, Elementos de Geometria a que apensou a doutrina das proporções, alguns teoremas de Arquimedes e a quadratriz de Dinostrato. Em 1737, o padre Campos imprimiu Tratado de Trigonometria plana e esférica e Synopse trigonometrica.

O percurso de Inácio Monteiro da Filosofia Antiga para a Nova é assinalável. Após a expulsão da Companhia de Jesus pelo Marquês (1759), Inácio Monteiro retirou-se para Itália onde publicou, em 1766, um Tratado de Física em sete volumes no qual refere o fastidioso aparato de silogismos dos escolásticos e reconhece que, na Física, ficam estes inteiramente aquém dos Modernos.

\section{Tentativas de renovação no Colégio das Artes}

Nos primeiros anos do século XVIII, no Colégio das Artes em Coimbra, bastião do pensamento aristotélico, há vislumbres de heterodoxia. É disso indício o seguinte extracto da Provisão de D. João V ao Reitor da Universidade de Coimbra:

... por haver notícia no meu tribunal da Consciência e Ordens que ... no Colégio das Artes ... se quer introduzir nas Cadeiras de Filosofia outra forma de lição da que até agora se observava e mandam os Estatutos, Hei por bem e vos mando que havendo nesta matéria alguma alteração, a façais evitar, fiando do vosso zelo, não consintais esta nova introdução.

Mais de trinta anos volvidos, as tentativas de renovação parecem persistir, pelo que o Reitor do Colégio das Artes afixa na portaria um Edital, onde determina que:

nos exames, lições, conclusões públicas ou particulares se não ensine... opiniões novas pouco recebidas ou inúteis para o estudo das ciências maiores como são as de Renato Descartes, Gassendi, Newton e outros, nomeadamente, qualquer ciência que defenda os átomos de Epicuro, 
ou negue a realidade dos acidentes eucarísticos, ou outras quaisquer conclusões opostas ao sistema de Aristóteles, o qual nestas escolas se deve seguir, como repetidas vezes se recomenda nos estatutos deste Colégio das Artes.

No reinado de D. João $\mathrm{V}$ é claro o reconhecimento da necessidade de uma reforma pedagógica no Reino. Mas os poderes instalados reagem. Jacob de Castro Sarmento tenta traduzir o Novum Organon de Bacon e a empresa é minada por Carbone.

\section{O «Verdadeiro Método de Estudar». Acção dos estrangeirados}

No primeiro meio século setecentista, as ideias reformadoras são protagonizadas por figuras como D. Luís da Cunha (1662-1749), Alexandre de Gusmão, o Conde da Ericeira (1673-1743) e seu círculo. D. Luís da Cunha defende um elenco de reformas sócio-políticas, económicas e culturais, considerando a Inquisição um vergonboso mal causador da ignorância, desprestígio e declínio do Reino. O impacto das novas correntes não se dissemina na sociedade portuguesa, distante desta elite esclarecida.

A divulgação em Lisboa do Verdadeiro Método de Estudar de Luís António Verney, em 1746, provocou viva polémica entre Antigos e Modernos, com troca de folhetos, livros, respostas e contra-respostas. Dedicada aos reverendíssimos Padres Mestres da veneravel religiam da Companhia de Jesus no reino e dominio de Portugal, a obra visava combater as suas doutrinas pedagógico-científicas, as suas explicações obscuras e defender a Filosofia Moderna, o conhecimento das coisas pelas causas e a verdadeira causa das coisas.

Verney acusa os peripatéticos (ou seja, os seguidores da Escolástica) de terem transformado a Física numa especulação impertinente, num conjunto de arengas que nada significam, afirmando que, em Portugal, não se sabe que coisa é Física, ainda aqueles que muito falam nela. 
Em vista de uma tal Filosofia física, facilmente se intui o estado da Matemática. O extracto seguinte é esclarecedor (op. cit., t.II, p.37):

Sei que a maior parte dos professores n'este reino consideram a Mathematica como alheia da Physica; e quando ouvem fallar em Mathematica, logo the perguntam — se hade chover ou fazer bom tempo; confundindo loucamente as conjecturas de alguns máos physicos e peores astrologos com a verdadeira Mathematica. [...] E finalmente, nunca vi Conclusões de Mathematica em que não houvessem risadas; de sorte que vão ás ditas conclusões como quem vae á comedia, porque entendem que são ridicularias que só servem para divertir.

Os Filósofos do Século XVIII estavam conscientes da importância que, para o progresso da Ciência, assume a descoberta de princípios unificadores das Leis da Natureza, e do papel primacial que, nesse contexto, cabe à linguagem simplificadora da Matemática. A investigação quantitativa dos fenómenos físicos encerra um ponto crucial da oposição dos Modernos à Escolástica. A conscencialização por parte dos Modernos de que a Matemática é uma disciplina fundamental à aquisição de resultados seguros, foi combatida pelos Antigos que consideravam tal aplicação um desvio inaceitável dos trilhos da Filosofia Natural.

As polémicas entre os adeptos da Filosofia Antiga de Aristóteles e seus seguidores, e os da Filosofia Moderna, constituem acontecimento peculiar na Cultura Portuguesa. Nas Recreações Filosóficas de Teodoro de Almeida, obra em dez volumes publicada entre 1751 e 1800, lê-se que, nos sermões de Quaresma e Advento, os pregadores persuadiam os crentes de que o novo Sistema Filosófico era contra o zelo da bonra de Deus, pelo que, do púlpito, exortavam ao ódio contra os autores hereges e seus seguidores.

A Filosofia Nova abala o corpo doutrinário da Companhia de Jesus. Enquanto alguns dos seus membros, obstinadamente refinavamos seus argumentos peripatéticos, outros, com maior liberdade de espírito, são permeáveis às novas doutrinas, aceitando-as como hipóteses. Mas, na transição de uma 
doutrina para a outra, a reinterpretação de Aristóteles era insuficiente, e os rumos de ruptura inevitáveis. A Escolástica estava inexoravelmente esgotada, a sua visão do mundo fora em definitivo substituída.

As críticas e reflexões sobre a realidade portuguesa expressas pelos estrangeirados face aos progressos dos países iluminados, desempenham papel relevante na futura reorganização dos estudos no Reino. Verney, Jacob de Castro Sarmento, Ribeiro Sanches, entre outros, são baluartes de uma nova mentalidade e o seu contacto com as luzes da Europa funciona como catalisador das reformas.

\section{As reformas de Pombal}

Em 1750, D. José I subiu ao trono e Sebastião José de Carvalho e Melo, futuro Marquês de Pombal, era seu Primeiro-Ministro. Importantes mudanças sócio-políticas têm lugar, a aristocracia perde influência, enquanto a burguesia emerge como nova classe dominante e um plano de revitalização económica do Reino toma corpo.

A política educativa do Marquês saldou-se em reformas de vulto. A reforma começou pelos estudos menores, com criação da Direcção Geral dos Estudos do Reino e nomeação do Principal Almeida para dirigir a reforma da instrução secundária. A abolição da Companhia de Jesus e as reformas da instrução pública no sentido da secularização do ensino constituem factos capitais da sua acção. Ribeiro Sanches (1699-1783) e o franciscano Frei Manuel do Cenáculo (1724-1814) foram os grandes inspiradores destas reformas, cujas linhas orientadoras são enunciadas nas suas obras, respectivamente, Cartas sobre a Educação da Mocidade (1760) e Cuidados Literários (1791).

Em 1761, tendo como objectivo formar uma elite aristocrática culta, é fundado o Real Colégio dos Nobres e criado um corpo de professores régios em substituição dos mestres religiosos, muitos deles jesuítas, expulsos do Reino em 1759 por crime de lesa-majestade. 
A criação do Colégio dos Nobres obedece ao ideário de Ribeiro Sanches, num primeiro esboço da futura Faculdade de Filosofia que, em Coimbra, irá substituir a proscrita Faculdade de Artes. Nos estatutos do Colégio dos Nobres, decreta-se a instituição de estudos públicos desconbecidos em Portugal, como o ensino da Physica geral e a experimental, das Matematicas elementares e transcendentes.

Por 1765 , começam a estar organizadas as disciplinas científicas no Colégio dos Nobres -Bonelli rege Arithetica, Geometriae Trigonometria, Franzini Algebra, Dalabella Physica experimental, Ponzoni é provido no Desenho e o matemático Ciera é nomeado prefeito de estudos.

Não vem esta medida a revelar-se consequente. Em poucas palavras se resume a acção pedagógica desta Instituição, onde se pretendia estabelecer um ensino médio de componente científica superior à humanística. Afirma um dos seus mais eruditos mestres:

Nos primeiros dez annos da sua existencia n'elle se criaram uns trinta fidalgos, dos quaes ahi estão e fazem vulto os que n'elle vingaram e se aproveitaram; mas, depois que deu esta primeira camada, nunca mais medrou nem luziu. (Ap. Revista de Educação e Ensino, 1892, p. 546).

Ao cabo de uma dezena de anos, a caducidade do Colégio dos Nobres levou à supressão, exarada em Carta Régia de 10 de Novembro de 1772, dos estudos de Matemática e Física. O sucesso da grande reforma, o desterro do sistema peripatético e instauração do sistema moderno, não se resolviam só com decretos, antes requeriam elementos que não se criavam de repente.

Em 1770, D. Francisco de Lemos é nomeado reitor da Universidade de Coimbra. É criada a Junta de Providência Literária, presidida por Pombal, para analisar a situação da Universidade e propor soluções no sentido de superar o estado das coisas. Em 1771, a Junta apresenta conclusões no Compendio bistorico do Estado da Universidade, os velhos Estatutos são suspensos. Em 1772, são promulgados os novos Estatutos. Os Estatutos de 1772 procuravam promover as Ciências da Natureza e as Ciências do Rigor, 
particularmente a Matemática, que, de acordo com o espírito racionalista da época, favorecia o desenvolvimento do espírito humano. O impulso dado à Física é também assinalável. As reformas incidiram sobre as várias Faculdades (Teologia, Leis, Canones e Medicina). Foram criadas duas novas faculdades: a Faculdade de Matemática e a de Filosofia Natural. Anexo à Matemática funcionava um Observatório Astronómico, e na dependência da Filosofia Natural um Museu de História Natural, um Gabinete de Física, um Laboratório Químico e um Jardim Botânico.

O relevo atribuído nos curricula universitários a matérias consagradas pela tradição, como Retórica e Filosofia Aristotélica, era revisto. A Reforma da Universidade de Coimbra tinha por objectivo primeiro a modernização dos curricula, dando especial ênfase à experimentação e especial protecção às Ciências Naturais e Matemáticas.

Os Modernos exaltavam a experiência como via de excelência para a investigação dos fenómenos naturais. A sua crença de que a experiência revelaria os segredos ocultos pelo véu da Natureza era inabalável. Já o filósofo inglês do século XIII, Roger Bacon proclamara o valor da observação e da experimentação na correcta interpretação e formulação das leis naturais. Os próprios Antigos fundavam na experiência os seus argumentos, defendendo assim que o Sol e as estrelas giravam em torno da Terra. Porém, com os Modernos o experimentalismo torna-se especialmente importante. As experiências atingiram grande popularidade e espectacularidade, ocorrendo em sessões sociais às quais todas as classes aderiam. O prestígio alcançado pela Filosofia Newtoniana provocou uma onda de curiosidade intelectual, constituíndo tema favorito nos círculos literários. À Ciência era reconhecido papel preponderante de progresso e de agente transformador da sociedade.

Nos horizontes dos sábios de então estava a busca de interdependências, de acumulação e sistematização de factos conducentes a leis gerais, cuja elaboração competia à Matemática. Às Matemáticas cabia o papel de aprofundar tanto o significado como o alcance das novas descobertas e ainda o de conduzir, não só a elaboração teórica, como a aplicação prática. 


\section{Os Estatutos de 1772: regulamento ou tratado científico?}

Os Estatutos de 1772 introduziram na Universidade uma reforma tão

extensa e profunda que foi por alguns considerada equivalente a uma nova fundação. Para além de preconizarem significativas mudanças curriculares e pedagógicas, instituíam políticas inovadoras de grande alcance e esclarecimento.

Os Estatutos procuravam organizar a investigação científica, criando os "Grémios das Faculdades», onde seriam admitidos os que tivessem concluído os cursos com mais "distinção e louvor» e teriam como destino ocupar de futuro as Cadeiras, segundo as provas sucessivas do seu Talento, Sciencia, e Capacidade.

Outro aspecto igualmente importante, consistia na publicação de compêndios pelos professores titulares, ou, em alternativa, a tradução por estes de livros de autores estrangeiros conceituados e actualizados.

A Reforma Pombalina da Universidade de Coimbra criava um corpo docente de profissionais da Ciência, o qual tinha por missão dedicar-se à criação científica e à produção de obras originais em língua portuguesa. Acaso estas medidas tivessem sido vigorosamente postas em prática, decerto teriam tido fortes repercussões científico-pedagógicas. Porém, como é tão frequente na nossa História, as leis existem mas não são cumpridas.

O erudito João Pedro Ribeiro considera os Estatutos na sua minúcia como «luxuario e exorbitante do seu objecto, a especifica declaração das doutrinas que se deviam ensinar em cada uma das aulas, subministrando até os professores definições triviaes, qual a de Egreja, divisões, etc., transformando um Regulamento de Estudos em um Tratado scientifico». De facto, a legislação é de tal modo especializada, no tocante a conteúdos e ao estabelecimento de preceitos pedagógicos, que, mais do que uma peça técnico-jurídica, se apresenta como um tratado.

Apesar do carácter quase exaustivo com que as diferentes matérias são analisadas, Teófilo Braga aponta a ausência de parte regulamentar para as 
promoções no magistério, requisito essencial para assegurar uma boa aquisição de pessoal docente. Tal lacuna parece ser explicável pela premência de abertura imediata das aulas. (p. 418-419).

\section{A Matemática na Reforma: Atitudes Inovadoras}

Tem as Mathematicas huma perfeição tão indisputável entre todos os conhecimentos naturaes, assim na excatidão luminosa do seu Methodo, como na sublime, e admiravel especulação das suas Doutrinas, que Ellas não sómente em rigor, ou com propriedade merecem o nome de Sciencias; mas tambem são as que tem acreditado singularmente a força, o engenho, e a sagacidade do Homem. (p. 141).

A Segunda Parte do Livro III dos Estatutos de 1772 diz respeito ao Curso Matemático. Eles representam um marco de mudança na História do ensino desta disciplina em Portugal. A criação da nova faculdade consagrada ao estudo da Matemática assenta numa filosofia de exaltação destas ciências, afirmando-se que uma Universidade destituída das suas huzes não seria mais do que hum cháos, semelhante ao Universo, se fosse privado dos resplandores do Sol. (p. 141).

A excelência da Matemática advém de ela conter em si mesma hum Systema grande de Doutrinas da maior importancia e, para além disso, notáveis aplicações noutras Artes — buma infinidade de outros subsidios ... de interesse à Causa pública. A exemplar exactidão do seu método, inspiradora do discernimento necessario para distinguir o Solido, do Frivolo; o Real, do Apparente; a Demonstração do Paralogismo, é considerada ... qualidade rara, e preciosa, imprescindível ao progresso dos conhecimentos gerais do Homem em qualquer objecto (p. 142). As Matemáticas não só caminham por buma estrada de luzes, desde os axiomas aos teoremas mais sublimes e recônditos, como iluminam superiormente todo o entendimento, precavendo contra os delirios da razão que haviam infeccionado a Universidade durante o domínio da Escolástica. Com argumentação deste teor se justifica o estabelecimento da Matemática como corpo de Faculdade. 
Depois do abandono a que os estudos matemáticos haviam sido votados, «deliberadamente para obnubilar os espíritos e os tiranizar com os delírios peripatéticos", é preconizado o seu cultivo por todos os estudantes de todos os cursos da Universidade. (Esta medida teve execução difícil, como revela a correspondência entre o Reitor-Reformador e o Marquês de Pombal.) Funcionavam três diferentes classes de estudantes matemáticos, a saber: classe de Ordinários, de Obrigados e de Voluntários. Cabe referir que o grau de exigência não era o mesmo para as diferentes classes. Aos Obrigados apenas se requeria a mediocridade, desde que se mostrassem hábeis nas matérias das suas Faculdades. Aos Ordinários a terceira reprovação em qualquer dos anos interditava a matrícula. Os Ordinários eram aqueles engenhos raros que cultivavam esta Ciência profundamente por amor de si mesma. Os Obrigados eram todos os estudantes de todas as outras Faculdades que a Matemática estudariam como complemento dos seus cursos — os alunos de Medicina durante os três primeiros anos, os dos cursos de Teologia e Cânones, seguiriam a Geometria do primeiro ano, porque aí se ensinava a Logica praticada com a maior perfeição, que be possivel ao entendimento ... (p. 151) Os Voluntários eram todos aqueles que, se não achando com forcas de genio para estudar a Mathematica de profissão, mas quisessem instruir por curiosidade e para ornamento do espírito, como convém a todas as classes, e em especial à Nobreza. Também os professores das diferentes Faculdades eram exortados a frequentar esta classe, dando exemplo aos estudantes do seu apreço por estas ciências, para que fossem cultivadas com o sucesso que requer o Bem commum do Reino ... E os que assim fizerem, serão preferidos por Mim nos concursos das suas Faculdades.

Este e outros privilégios eram concedidos aos que cursassem Matemáticas. Aos fidalgos era contado o tempo do curso como serviço vivo em campanha e aos Doutores concedida a mercê do hábito de qualquer das Ordens Militares do Reino. Aos que fossem servir na Marinha ou na Engenharia eram admitidos com vantagem e dispensados de outras provas. Em simultâneo, os que desdourassem estes estudos incorreriam no real desagrado... 
Na áspera luta da Razão contra o Obscurantismo, cria-se que a Matemática desempenharia papel de excepção. A excelência das suas doutrinas de tão alta especulação, a firmeza do seu método, a sua fecundidade e as suas luzes rasgariam as trevas de ignorância do Reino.

O Título IV do Livro III, parte II, dos Estatutos diz respeito à organização do Curso Matemático. As cadeiras são Geometria, Álgebra, Foronomia (ou seja, Física Matemática) e Astronomia, uma em cada ano. Os italianos Ciera e Franzini regem, respectivamente, Astronomia e Álgebra, e o ex-jesuíta Monteiro da Rocha Foronomia. A Geometria é confiada ao tenente de artilharia da Praça de Valença, José Anastácio da Cunha, o qual, por nomeação de Pombal, é feito lente antes de ser doutor, tendo por certo que fará bom ornamento na novel Faculdade.

Os conteúdos programáticos dos cursos são rigorosamente delineados, descendo ao ínfimo pormenor, os objectivos claramente enunciados, os métodos de ensino explicitados. Na Geometria, o objectivo essencial era o ensino das verdades elementares de Euclides, seguindo como texto os Elementos. Na Álgebra, estudava-se o cálculo diferencial directo e inverso, com aplicação à Geometria Sublime e Transcendente, as cónicas (analiticamente), as séries e a resolução de equações. A Astronomia era dedicada à teoria do movimento dos astros e à prática das observações astronómicas. (A Foronomia será analisada com maior pormenor no parágrafo que adiante se lhe dedica).

Os métodos a usar nos diferentes cursos são criteriosamente especificados, ensinando-se, com espantosa actualidade e lucidez, a ensinar e a estudar Matemática. Esse estudo, por requerer grande esforço, constância, reflexão, obriga a uma particular aplicação. Os objectivos prioritários a atingir são, por um lado, a memória das verdades e o entendimento das demonstrações, por outro lado, o envolvimento das forças do engenho na indagação de novos conbecimentos. O estudante era exortado a desempenhar papel activo no processo de aprendizagem, a combinar por si mesmo o já conhecido e a indagar novas verdades, nunca se devendo limitar ao papel de mero retransmissor. 
Cuidaráõ tambem muito os mesmos Lentes, em que os Discipulos se ponham no caminho de Inventores: Presentando-lhes, para isso algumas materias pelos passos, que se deram, ou podiam dar, até se chegar ao descobrimento das verdades, que nellas se contém: Mostrando-lhes os indicios por onde se suspeita, e conjectura primeiro o que se poderá achar: e os meios e tentativas que se aplicam para o descubrir.

São modelares os preceitos pedagógicos a desenvolver nas sessões de Exercícios Vocais, Exercícios por Escrito, Exercícios Práticos (como Prática de Geodesia, Cálculos Astronómicos, ou Prática das Observações). O Mestre deve sensibilizar para as soluções mais elegantes e perfeitas, emendar os defeitos dos discípulos, mostrando aos de génio mais embaraçado como chegar à solução, mas somente depois de o próprio ter feito por si mesmo todas as diligências para vencer os obstáculos.

No início de cada curso, nos Prolegómenos Gerais, era concedido devido relevo à História dos conceitos, de modo a instruir o estudante nas antigas descobertas e a salvaguardá-lo do risco de tentar descobrir coisas já sabidas. A História surgia, assim, como fundamentadora de todo o saber. Mas, se os aspectos históricos eram apontados como de grande importância, as aplicações estavam entre os objectivos primordiais dos cursos. No espírito da Reforma, a concepção utilitarista da Ciência é nota dominante. As aplicações da Matemática constituem ponto primacial. As mostras das aplicações e uso das doutrinas sempre deverão ser expostas, pois estas se não reduzem a meras especulações. Esta ênfase nas aplicações compreendese como reacção à orientação anterior dos estudos, sobretudo de natureza especulativa.

Deixar os Estudantes volverem-se nos seus Conhecimentos Theoricos, sem entrarem no Exercicio Pratico dos Principios Cientificos, que aprenderam, he destituir as Sciencias dos seus fins; he impedir que o Estado receba a utilidade que delles dimanam; he arruinar o Ensino das mesmas Sciencias; he desanimar os Espiritos para se não aplicarem a ellas; he confirmar os ignorantes no prejudicial, e errado conceito, de que estes Estudos são inuteis, ou de pura curiosidade... 


\section{A Foronomia}

Na nova Faculdade de Filosofia, ensinava-se Filosofia Racional e Moral, História Natural, Física Experimental e Química Teórica e Prática. A cadeira de Física da Quantidade fazia parte do Curso Matemático, ministrado na recém-criada Faculdade de Matemática. O que distinguia a Física da Qualidade da Física da Quantidade? Nos Estatutos de 1772, foi claramente estabelecida a distinção entre ambas, sendo definidos com minúcia os respectivos objectivos. Enquanto que, na Física da Qualidade, se incluem os factos conbecidos pela experiencia; que be huma observação mais subtil, procurada por artificio para descobrir o véo da Natureza; e para lhe perguntar os segredos mais reconditos das suas operações, quando ella por si mesma não falla, a Física da Quantidade identifica-se com a Foronomia, ou seja:

a Sciencia completa do Movimento, tanto dos Sólidos como dos Fluidos; e se comprehendem todos os Ramos subalternos das Sciencias Physico-Mathematicas; como são; a Statica; a Hydrostatica; a Mecanica e Hydraulica; a Dioptrica, Catoptrica; e todas as mais Sciencias, em que são tratados Fenomenos, e effeitos, que de qualquer modo resultam do Movimento dos córpos; e se podem determinar por Cálculo, e Geometria.

O conhecimento da Física Moderna exigia uma preparação Matemática adequada. Segundo Verney, a separação entre a Física e a Matemática entrara nas nossas escolas nos séculos da ignorância, ao longo dos quais os peripatéticos transformaram a Física numa especulação. O excerto seguinte dá conta do grande relevo que nos Estatutos é dado à Matemática (elevada a posição cimeira na hierarquia das Ciências) como disciplina subsidiária da Física:

Por esta razão he maniffesto, que a Fysica da quantidade, ou as Sciencias Fysico-Mathematicas, não devem ter lugar senão no Curso Mathematico, depois das Sciencias Exactas, que servem de Instrumento para as conduzir até aos mais sublimes, e importantes consequencias. Deve porém advertir-se, que a Mathematica faz tudo nestas Sciencias; exceptuando sempre os Principios fundamentais que devem tirar-se da experiencia. 
Àcerca da Física da Quantidade afirmam os Estatutos:

Os Filosofos que não possuem as Mathematicas com a profundidade necessaria, não passam das Sciencias do Movimento, mais que pela superficie. Contentam-se de raciocinar em geral sobre os Fenomenos, e effeitos: Procurando descubrir as causas delles. Mas sendo por sua natureza muito vacillante esta especie de raciocinio; e faltando-lhe a Sciencia de calcular exactamente os ditos effeitos, para ver se correspondem ás causas suppostas; ficam sempre vagando pelo paiz das conjecturas...

Os Estatutos de 1772 dão à Física da Quantidade grande relevo, não só pela importância teórica de que esta se reveste, mas também por se reconhecer a utilidade da sua aplicação prática em empresas de carácter tecnológico, como se depreende da seguinte transcrição:

Em todos estes Tratados se contém a parte mais sublime da Física, promovida de um modo scientifico, e util ao progresso, e aperfeiçoamento das Artes cujo instrumento be o mesmo Movimento.

O desenvolvimento dos conhecimentos científicos susceptíveis de aplicação às artes, ou seja, às tecnologias, era tido em alta conta. Caracterizemos de forma mais completa o âmbito da Física da Quantidade. Ao Lente desta Cadeira se prescreve o seguinte:

... terá pois grande cuidado em explicar com toda a clareza, e distinção possivel os Principios fundamentais, tanto geraes como particulares de cada bum dos Tratados da sua Repartição. E subindo dos ditos Principios por meio de huma cadeia de raciocinios Mathematicos, fundados, e dirigidos pelos methodos mais efficazes do Cálculo, e da Geometria; conduzirá os seus Ouvintes até ás ultimas consequencias, a que póde chegar a industria do homem nestas materias; ... Por isso não entrará no exame das Forças Motrizes; Entes Metafysicos e escuros ...Bastando considerar os effeitos destas Forças, sem pretender decifrar a natureza escura dellas: E sendo para isso sufficientes tres unicos Principios que são: $I^{\circ}$ inercia dos corpos: $I I^{\circ}$ A composição e descomposição do movimento: $I I I^{\circ}$ O Equilibrio de dous corpos iguaes em distancias iguaes do eixo do 
movimento: Sobre elles se fundará o edificio sólido da mesma Sciencia; cuja Theorica, enquanto se não introduzirem Principios vacillantes, não será menos exacta que a Geometria mesma... Daqui passará ás Sciencias que tem a luz por objecto. E deixando a questão escura da natureza da mesma luz, estabelecerá os principios fundamentaes das ditas Sciencias, que se reduzem a tres: $I^{\circ}$ Que a luz se propaga por huma linha recta: $I I^{\circ}$ Que se reflecte por hum angulo igual ao angulo de incidencia: III Que ao entrar, e sabir por meios diafanos de differente densidade se refrange por certas Leis, que pela experiência se determinam. Estes tres Principios servirão de base para a Dioptrica e Catoptrica sendo tudo o mais Cálculo e Geometria.

\section{A Viradeira - Reacções contra as Reformas Pombalinas}

Com o afastamento do Marquês de Pombal, regressam ao Reino alguns dos seus opositores, como o Duque de Lafões (1719-1806), o abade Correia da Serra (1750-1823) e o oratoriano Teodoro de Almeida (1722-1804), que fundam em 1799 a Academia Real das Ciências de Lisboa.

Depois da morte de D. José, as forças que Pombal antagonizara emergem, entre elas a Inquisição. "Com intuito de arruinar o estabelecimento da Nova Reforma», desferem-se calúnias e ataques contra a Universidade, foco de doutrinas novas, peregrinas e perigosas. Os estudantes da Reforma são acusados de pensarem livremente em pontos de religião e o Reitor-Reformador elabora um importante documento de defesa: a Relação Geral do Estado da Universidade (1777). Aí escreve D. Francisco de Lemos a ensejo da frequência do Curso de Matemáticas:

No Primeiro Anno se matricularam oito Estudantes, como Ordinários; dos quaes hum morreu, e dous dezertaram; ficando só cinco continuando os Estudos; os quaes se acham já Formados na Faculdade de Mathematica: No Segundo matricularam-se dous, dos quaes bum faltou: No Terceiro, Quarto, e neste Ano, que he o Quinto, nem hum ...

Anastácio da Cunha apresentou à Congregação da Faculdade - órgão que deliberava sobre escolha dos manuais - os Principios Mathematicos. A 
obra, que mereceu juízo favorável de uma autoridade como Gauss (Príncipe das Matemáticas) e incluindo contributos originais no domínio da Análise, conheceria a rejeição da Congregação pelo silêncio. Os alunos de Anastácio envolvem-se numa espécie de sublevação contra o mestre, com elevado padrão de exigência e verdadeiramente apostado em ensinar deveras.

Em 1778, o lente de Geometria José Anastácio da Cunha é preso na Santa Inquisição da Sofia por culpas de libertinismo e beresia, revelando o seu processo o estado mental de intolerância da sociedade portuguesa. A cátedra de Geometria fica vaga e a Universidade indiferente à perseguição movida contra este seu ilustre professor, personalidade marcante da cultura portuguesa. O lente é penitenciado a três anos de reclusão na Casa do Oratório das Necessidades, quatro anos de degredo em Évora e proibido de entrar em Coimbra. Nove meses volvidos é indultado e nomeado, por decisão de Pina Manique, professor de Matemática e Director do Colégio de São Lucas da Casa Pia. Aí ensinou meninos desvalidos, cargo desajustado ao seu talento. Daqui vêm cursar Matemáticas em Coimbra alguns de seus discípulos, José Joaquim Rivara, Manuel Pedro de Melo e Tristão Álvares da Silveira. O infortúnio de Anastácio da Cunha parece talhado à medida do seu génio. Envolve-se em polémica com Monteiro da Rocha, discutindo prioridade de descoberta numa questão a concurso na Academia das Ciências de Lisboa. Anastácio da Cunha morreu prematuramente aos 43 anos, em dia de Ano Novo e depois de concluir a revisão dos Princípios. Caso raro no panorama português, deixa escola. Manuel Pedro de Melo será lente de Hidrodinâmica em Coimbra, enquanto outros dos seus discípulos, como João Manuel de Abreu e os irmãos D. Rodrigo e D. Domingos de Sousa Coutinho, perseguidos, abandonam o Reino. Mas, no estrangeiro, cuidam da divulgação internacional da obra do mestre. Os Princípios são publicados postumamente. Uma segunda edição saiu em francês e o Ensaio sobre os princípios da Mecânica foi publicado em Londres em 1807. Também a sua obra poética, na transição para o Romantismo, veio à luz postumamente.

Os efeitos práticos das reformas, positivos e imprescindíveis à modernização do meio científico-cultural português, ficaram aquém das expectativas. 
No tocante à institucionalização da Ciência e seu estabelecimento em bases profissionais, não se cumpriu o preconizado. O peso político na nomeação de cargos de topo na carreira, amiúde vitalícios, subverteu o espírito dos Estatutos, no seu intento de renovação da comunidade científica na Universidade, com devido reconhecimento da criatividade. Anastácio, por exemplo, foi afastado e nunca reintegrado.

Só muito ocasionalmente os cientistas portugueses criaram obra ao nível dos seus congéneres europeus. O surgimento de mecanismos autónomos de produção de saber não ocorreu, pelo menos de modo estruturado. A sociedade portuguesa, com um índice de analfabetismo altíssimo, era meio pouco propício à difusão e sedimentação das novas práticas e ideários científicos. Estes circunscreviam-se a elites esclarecidas e a sua propagação a outros extractos não passou da incipiência. As intromissões dos poderes político e clerical na comunidade científica, controladores e prepotentes, em nada favoreceram o florescimento da Ciência em Portugal.

Conforme decretado nos Estatutos, foram traduzidas para português importantes obras. Na Matemática, textos fundamentais como os Elementos de Euclides (1792) e o Tratado de Análise de Bezout (1774) foram publicados. Salvo casos isolados, os objectivos dos homens de Ciência portugueses centraram-se mais na reprodução do saber, na adopção das obras estrangeiras, que na produção de saber original. Reproduzimos de Voyage au Portugal depuis 1797-1799 (Paris, 1803), pp. 393-394, de H.F. Link, um esclarecedor extracto sobre a realidade científica portuguesa em finais de Setecentos:

... Le principal défaut, c'est qu'on n'a pas encore acquis le goût des sciences, ou qu'on ignore l'art de l'inspirer ... Le Portugal possède des bommes qui connaissent l'état actuel de la littérature. Il y a beaucoup d'excellentes têtes, mais il est difficile de trouver dans ce pays des savants profonds, qui cultivent les sciences uniquement par l'amour pour elles. La raison pour laquelle cette université est en général si peut utile n'est pas difficile à deviner. D'abord dans un pays ou l'on est obligé de faire imprimer ses écrits sans rétribuition et à ses dépens, ou, avec beaucoup de peine, à ceux du Roi, les auteurs doivent être bien rares, mais d'où vient 
donc cette indolence pour les sciences? et pourquoi la vente des livres ne compense-t-elle jamais les frais de l'impression? Une censure sévère, un tribunal de l'Inquisition, toujours redoutable pour les écrivains, suffisent pour éteindre toute ardeur pour l'étude.

\section{REFERÊNCIAS BIBLIOGRÁFICAS}

1. Teodoro de Almeida, Recreação Filosófica, 10 vols., Lisboa, 1751-1800.

2. N. Bebiano, Mathematical Horizons in Portugal in the $18^{\text {th }}$ Century, Historia Mathematica, 23 (1996) 239-245

3. N. Bebiano, O culto das musas pelos matemáticos de Coimbra, Universidade(s). História. Memória. Perspectivas, Actas do Congresso "História da Universidade», Coimbra (1991), Vol. 4 111-126.

4. Teófilo Braga, História da Universidade de Coimbra, Vol. III, Lisboa, 1899

5. Rómulo de Carvalho, História do Gabinete de Física da Universidade de Coimbra, Universidade de Coimbra, Biblioteca Geral, 1978

6. Rómulo de Carvalho, A Física experimental em Portugal no séc. XVIII, Instituto de Cultura e Língua portuguesa, Lisboa, 1982

7. Rómulo de Carvalho, "A Física na reforma pombalina", História e desenvolvimento da ciência em Portugal, Academia das Ciências de Lisboa, 1986, [Reproduzido em Actividades científicas em Portugal no séc. XVIII, Universidade de Évora, 1996]

8. Rómulo de Carvalho, A pretensa descoberta da lei das acções magnéticas por dalla Bella, em 1781, na Universidade de Coimbra, Revista Filosófica - Ano IV n. ${ }^{\circ} 11$ Coimbra, 1954.

9. Francisco de Lemos, Relação Geral do Estado da Universidade (1777), Por Ordem da Universidade, Coimbra, 1980

10. Mário A. Silva, Um novo Museu em Coimbra - o Museu Pombalino de Física da Faculdade de Ciências da Universidade, Revista da Faculdade de Ciências da Universidade de Coimbra, n. ${ }^{\circ} 1$, vol. VIII $129-154$

11. Mário A. Silva, A actividade científica dos primeiros directores do Gabinete de Física que a reforma pombalina criou em Coimbra, em 1772, Publications du Laboratoire de Physique de l'Université de Coimbra, n. ${ }^{\circ} 4,155-198$

12. Ana Simões, Um novo olhar pela ciência no Portugal setecentista, Texto da Conferência no Departamento de Física da Universidade de Coimbra, 21 de Março de 1997.

13. Luís António Verney, Verdadeiro Método de Estudar, 5 vols. Sá da Costa, 1949-1952, Lisboa

14. Estatutos da Universidade de Coimbra (1772), Livro III, Por Ordem da Universidade, Coimbra, 1972.

15. O Humanismo Português 1500-1600, Publicações do II Centenário da Academia das Ciências de Lisboa, 1988.

16. Les Mécanismes du Génie, Editor Responsável: Dr. Robert de Smet, Europália 91, Portugal, 1991.

17. O Engenho e a Arte, Colecção de Instrumentos do Real Gabinete de Física, Universidade de Coimbra e Fundação Calouste Gulbenkian, 1997. 